\title{
Propagation of environmental risk from contaminant transport through groundwater and stream networks
}

\author{
K. Persson, J. Jarsjö, C. Prieto \& G. Destouni \\ Department of Physical Geography and Quaternary Geology, \\ Stockholm University, Sweden
}

\begin{abstract}
We use a Lagrangian stochastic advective-reactive (LaSAR) approach to model coupled groundwater and surface water contaminant transport. In this approach, physical (advective) solute travel time distributions constitute main functions for the contaminant transport representation. In a specific catchment area case study, we show how these travel time distributions, for separate groundwater and stream network systems and for the linked groundwater-stream systems of whole catchments, can be modelled and quantified from available field data. We further use the LaSAR modelling approach in an extreme-scenario methodology for investigating how the risk (probability) of concentrations exceeding given environmental or health-based concentration limits may propagate downstream of a contaminant source for various spatial source extents and contaminant release magnitudes and dynamics under different aquifer conditions. Results show that the average relation between characteristic advective transport and natural attenuation time scales is essential and in some (with results identifying also in which) cases sufficient information for assessing if and where this risk may decline below acceptable levels downstream of the source zone. The presented general quantification methodology and specific exemplification results may provide useful guidelines for emergency remediation of contaminated land sites and for prioritisation decisions and scoping calculations to focus further investigations of long-term remediation options on critical site and contaminant parameters.
\end{abstract}

Keywords: contaminated land, solute transport, stochastic modelling, environmental risk analysis, GIS. 


\section{Introduction}

The estimation of future concentrations and mass flows of contaminants in groundwater and surface water downstream of contaminated land sites requires mathematical modelling. However, model predictions are commonly associated with large uncertainties, due to e.g. lack of data, model simplifications, and heterogeneity of physical and biogeochemical aquifer properties $[1,2]$. A relevant analysis of environmental and health risks posed by contaminant migration must account for such uncertainties. One of the main problems with catchment-scale contaminant migration modelling is that essential contaminant transport characteristics (such as transport pathways, velocities and associated travel distances or travel times) are not well known. The main aim of the present study is to investigate how such uncertainty may affect environmental risk.

We use a Lagrangian stochastic advective-reactive (LaSAR) approach [e.g., 3-5] to model coupled groundwater-stream transport of a contaminant through a catchment area and account for associated transport uncertainties. Probability density functions (pdfs) of physical (advective) solute travel times to any distance downstream of the contaminant source are main model components in this approach. In a first theoretical part of the paper, we describe how the LaSAR approach may be used to assess the risk (probability) of contaminant concentrations to exceed given environmental or health-based limits. In the second part of the paper, we put the theory into a site-specific application by GIS-based modelling of contaminant transport through the coupled groundwaterstream system of a coastal catchment area. For this case study, we quantify the statistics of contaminant mass delivery to coastal outlets resulting from contaminant release at different locations in the catchment area.

\section{Materials and method}

\subsection{Theoretical extreme scenario analysis}

Fig. 1 illustrates schematically the problem considered in the theoretical part of this study: Contaminants from a contaminated land site reach the groundwater table within a source zone of length $x_{s}$ along the mean groundwater flow direction. The contaminants may be transported towards an environmental compliance boundary at distance $x_{1}$ downstream of the source zone. The probability, or risk $S_{R}$, that a given environmental concentration limit $C_{T}$ will be exceeded by any local concentration $C$ on the compliance boundary at $x_{1}$ at any time $t$ can be estimated from the concentration pdf $f\left(C\left(t, x_{1}\right)\right.$, which, for simplicity and result exemplification, we assume here to be lognormal. Thereby, $f\left(C\left(t, x_{1}\right)\right)$ is fully determined by the two most readily obtainable concentration statistics: the expected value $E\left[C\left(t, x_{1}\right)\right]$ and variance $V\left[C\left(t, x_{1}\right)\right]$.

We evaluate $E\left[C\left(t, x_{1}\right)\right]$ and $V\left[C\left(t, x_{1}\right)\right]$ for two different scenarios for contaminant release from the source zone: i) a short-pulse release scenario, which may for example represent a first, fast release phase of soluble compounds after a chemical accident at the soil surface; and ii) a long-lasting continuous 
leakage scenario, which may for example represent long-term industrial leakage, or a second slow leakage phase after a chemical accident, when some hydrophobic contaminant fraction slowly leaks out from the source zone over long time.

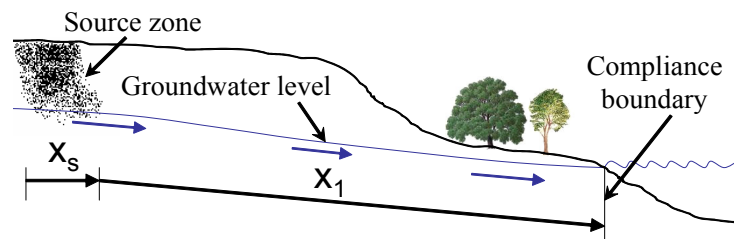

Figure 1: Schematic illustration of a contaminated land source zone of extent $x_{s}$ along the mean groundwater flow direction with an environmental compliance boundary being located at some arbitrary distance $x_{1}$ downstream of the source zone boundary at $x_{s}$.

In the following, we investigate the possible downstream propagation of the risk $S_{R}$ for these two extreme contaminant input scenarios and for two extreme cases of aquifer heterogeneity structure. The aquifer heterogeneity structure affects the advective solute travel time pdf $g_{1}\left(T, x_{1}\right)$, which, in turn, affects the concentration statistics. The first investigated aquifer case is a stratified aquifer, where the advective velocity of groundwater transport is constant in the mean flow direction along any individual streamline, but varies randomly, due to the random variation of hydraulic conductivity, between different streamlines. The second aquifer case is an isotropic aquifer, where hydraulic conductivity and advective groundwater transport velocity vary randomly with equal spatial correlation lengths in all three spatial directions. In both cases, we assume that the hydraulic conductivity is lognormally distributed and refer to $[4,5]$ for derivations of travel time statistics needed for evaluating $g_{1}\left(T, x_{1}\right), E\left[C\left(t, x_{1}\right)\right]$ and $V\left[C\left(t, x_{1}\right)\right]$ in the different contaminant release scenarios and aquifer cases.

\subsection{Application to the Forsmark coastal catchment area}

In the second part of this study, we link the LaSAR contaminant transport methodology described above to GIS-based hydrologic modelling [6, 7] in order to model contaminant transport through the coupled groundwater- surface water system of a specific coastal catchment area. The area is one of the candidate sites for the final repository of nuclear waste in Sweden: the flat coastal area of Forsmark (Fig. 2), 100km north of Stockholm.

As input for the transport pathway, velocity and travel time calculations, we use raster maps of precipitation, calibrated evapotranspiration, runoff, vegetation, soil texture, slope, and flow directions, which were produced by Jarsjö et al. $[6,7]$. The model area covers $29 \mathrm{~km}^{2}$ and the grid cell resolution is $10 \times 10 \mathrm{~m}$.

We calculate the mean groundwater flow velocity for each $10 \times 10 \mathrm{~m}$ cell as $v=K($ gradient $) / n$, where $K$ is the mean hydraulic conductivity, gradient is the hydraulic gradient, and $n$ is the mean effective porosity. Based on available field 
data [8], we assume that $K=1.5^{*} 10^{-5} \mathrm{~m} / \mathrm{s}$ and $n=0.05$ in the whole model area. We further assume that within the sub-catchment of each coastal outlet cell, the hydraulic gradient equals the mean ground slope of all sub-catchment cells, so that the hydraulic gradient is constant along each streamline.

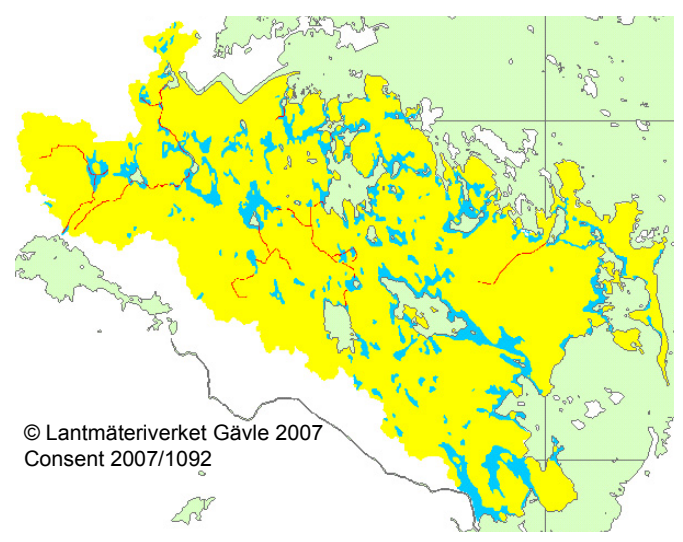

Figure 2: The model area of Forsmark (medium grey), with black lines representing streams, light grey areas representing lakes and sea, and dark grey areas representing wetlands.

Lakes, streams and wetlands cover $19 \%$ of the total model area. We define the solute travel time through a lake or wetland as $T_{\text {Res }}=A d_{\text {eff }} / Q$, where $A$ is the area of the lake or wetland, $d_{\text {eff }}$ is the mean effective depth, and $Q$ is the modelled $[6,7]$ mean annual discharge to the lake/wetland. The mean effective depth in a wetland is defined as the product of the depth and the water content. In the lakes, $d_{\text {eff }}$ is simply the mean depth. The travel time in streams is defined as the mean flow velocity divided by the stream length. The mean flow velocity is defined as $v=Q A_{\text {str }}$, where $Q$ is the modelled mean annual flow rate $[6,7]$ and $A_{\text {str }}$ is the mean cross-section area of the stream. We estimate or assume values of $d_{\text {eff }}$, water content in wetlands and $A_{\text {str }}$ based on field data reported in [9-12]. For isolated lakes and wetlands that do not belong to the surface water network that is connected with the sea, we assume an effective flow velocity $v=L_{e f f} / T_{\text {Res }}$, where $L_{\text {eff }}=\operatorname{sqrt}(4 A / \pi)$ is an effective flow length.

When we have assigned a flow velocity $v$ to all cells and computed travel times in lakes, streams and wetlands, we can calculate a mean physical travel time $T$ from each cell in the model area to a coastal outlet.

Due to variability and uncertainty in transport velocities (due to e.g. the variable hydraulic conductivity in the catchment [8]) and pathways, the solute travel time $T$ from any given input location within the catchment to the coast may vary greatly. We exemplify how such travel time variability may affect model results by assuming that the travel time from each cell is lognormally distributed around the cell-specific mean advective travel time with a moderate travel time variance of $V[\ln T]=1$. A lognormal pdf $g_{1}(T)$ of solute travel time from each cell to the coast is generated from 100000 
Monte Carlo simulations (more than sufficient for stable statistics results). The expected value $\left(E[\alpha]=\int_{0}^{\infty} \exp [-\lambda T] g_{1}\left(T ; x_{1}\right) d T\right)$ and variance $\left(V[\alpha]=\int_{0}^{\infty} \exp [-2 \lambda T] g_{1}\left(T ; x_{1}\right) d T-(E[\alpha])^{2}\right)$ of the contaminant mass delivery fraction $\alpha=\exp [-\lambda T]$ that may reach the coast after a given mass input at each cell is further computed for different first-order contaminant attenuation rates $\lambda\left[\mathrm{T}^{-1}\right]$ For continuous contaminant release, $\alpha$ also represents the steady state contaminant concentration in the coastal discharge relative to the constant concentration of solute mass input. For derivation of $E[\alpha]$ and $V[\alpha]$, we refer to [4].

\section{Results and discussion}

\subsection{Theoretical extreme scenario analysis}

In this section, we consider the different extreme contaminant release scenarios and aquifer cases described in Section 2.1 for assessing the risk propagation downstream of a contaminant source in the general transport problem shown in Figure 1. Table 1 shows the relative distances $x_{1} / x_{s}$ from the contaminant source zone where the risk $S_{R}$ to exceed different relative concentration limits $\left(C_{T} / \mathrm{C}_{0}=\right.$ $0.001-0.1$ ) falls below $1 \%$. The $1 \%$ risk level is chosen as an example of one possible societal risk acceptance level. $C_{0}$ is the solute concentration in the water that leaves the source zone at $x_{s}$. We assume that the migrating contaminants undergo irreversible first-order attenuation, due to degradation, removal or decay processes, and have normalised the attenuation rate $\lambda$ as: $\lambda\left(n x_{s}\right) /\left(K_{g}\right)$, where $n$ is the (assumed constant) aquifer porosity, $K_{g}$ is the geometric mean of the (assumed random and log-normally distributed) hydraulic conductivity $K$, and $J$ is the mean hydraulic gradient in the mean flow direction. The normalising term $\left(K_{g} J\right) /\left(n x_{s}\right)$ corresponds to the arithmetic mean in the isotropic aquifer and the geometric mean in the stratified aquifer of the advective solute travel time through the source zone extent $x_{s}$. The normalised attenuation rate represents thus a time-scale ratio between a characteristic attenuation time $1 / \lambda$ and a characteristic mean advective travel time $\left(K_{g} J\right) /\left(n x_{s}\right)$; the constant source zone extent $x_{s}$ is included here instead of the variable transport distance $x_{1}$ in order for the normalising term to be constant.

Results in Table 1 are based on the example relative correlation length of hydraulic conductivity $I / x_{s}=0.1$ for the isotropic aquifer case. Shorter correlation length $I$ compared to the transport distance $x_{1}$ implies that differences in travel times between different streamlines are averaged out more than for longer $I$. In the stratified aquifer case, $I$ is by definition infinite in the mean flow direction, and the travel time variability is much larger than in an isotropic aquifer with the same hydraulic conductivity variance $V[\ln K]$.

Large travel time variability implies that travel time in many streamlines deviates significantly from the mean travel time. Attenuation along the fastest streamlines will then be much lower than along streamlines that are closer to the 
mean. The transport along streamlines with much longer than average travel times, on the other hand, does not affect total contaminant mass delivery much if the mean travel time is already long enough for most of the contaminant to be attenuated. However, large travel time variability may also decrease downstream concentrations since it increases the spreading of the migrating contaminant plume. If the contaminant release is a short pulse rather than continuous in time, the solute thereby becomes more diluted.

Table 1: $\quad$ Relative transport distance $x_{1} / x_{s}$ at which the risk $S_{R}$ to exceed the relative concentration limit $C_{T} / C_{0}$ falls below $1 \%$ for different relative attenuation rates $\lambda\left(n x_{s}\right) /\left(K_{g} J\right)$.

\begin{tabular}{|c|c|c|c|c|c|c|c|}
\hline \multirow[b]{3}{*}{$C_{T} / C_{0}$} & \multirow[b]{3}{*}{$\begin{array}{l}\text { Aquifer } \\
\text { hetero- } \\
\text { geneity } \\
\text { structure }\end{array}$} & \multicolumn{6}{|c|}{$\lambda\left(n x_{S}\right) /\left(K_{g}\right)$} \\
\hline & & \multicolumn{2}{|c|}{$\leq 0.01$} & \multicolumn{2}{|l|}{0.1} & \multicolumn{2}{|l|}{$\geq 1$} \\
\hline & & $\begin{array}{l}\text { Short- } \\
\text { pulse } \\
\text { release }\end{array}$ & $\begin{array}{l}\text { Long- } \\
\text { lasting } \\
\text { leakage }\end{array}$ & $\begin{array}{l}\text { Short- } \\
\text { pulse } \\
\text { release }\end{array}$ & $\begin{array}{l}\text { Long- } \\
\text { lasting } \\
\text { leakage }\end{array}$ & $\begin{array}{l}\text { Short- } \\
\text { pulse } \\
\text { release }\end{array}$ & $\begin{array}{l}\text { Long- } \\
\text { lasting } \\
\text { leakage }\end{array}$ \\
\hline \multirow[t]{2}{*}{0.1} & $\begin{array}{l}\text { stratified } \\
\text { aquifer }\end{array}$ & $\begin{array}{l}>40^{\alpha} \\
>60^{\beta}\end{array}$ & $>300^{\alpha}$ & $\approx 20^{\alpha \beta}$ & $\begin{array}{l}\approx 170^{\alpha} \\
\approx 70^{\beta}\end{array}$ & \multirow[t]{2}{*}{$<10^{\alpha \beta}$} & $\begin{array}{l}<20^{\alpha} \\
<10^{\beta}\end{array}$ \\
\hline & $\begin{array}{l}\text { isotropic } \\
\text { aquifer }\end{array}$ & $\begin{array}{l}>250^{\alpha} \\
>280^{\beta}\end{array}$ & $\begin{array}{l}>250^{\alpha} \\
>240^{\beta}\end{array}$ & $\approx 40^{\alpha \beta}$ & $\approx 30^{\alpha \beta}$ & & $<10^{\alpha \beta}$ \\
\hline \multirow[t]{2}{*}{0.01} & $\begin{array}{l}\text { stratified } \\
\text { aquifer }\end{array}$ & $\begin{array}{l}>180^{\alpha} \\
>200^{\beta}\end{array}$ & \multirow[t]{2}{*}{$>300^{\alpha \beta}$} & $\begin{array}{l}\approx 60^{\alpha} \\
\approx 50^{\beta}\end{array}$ & $\begin{array}{l}>300^{\alpha} \\
\approx 150^{\beta}\end{array}$ & \multirow[t]{2}{*}{$<10^{\alpha \beta}$} & $\begin{array}{l}<50^{\alpha} \\
<20^{\beta}\end{array}$ \\
\hline & $\begin{array}{l}\text { isotropic } \\
\text { aquifer }\end{array}$ & $>300^{\alpha \beta}$ & & $\approx 60^{\alpha \beta}$ & $\approx 50^{\alpha \beta}$ & & $<10^{\alpha \beta}$ \\
\hline \multirow[t]{2}{*}{0.001} & $\begin{array}{l}\text { stratified } \\
\text { aquifer }\end{array}$ & \multirow[t]{2}{*}{$>300^{\alpha \beta}$} & \multirow[t]{2}{*}{$>300^{\alpha \beta}$} & $\begin{array}{l}\approx 120^{\alpha} \\
\approx 80^{\beta}\end{array}$ & $\begin{array}{l}>300^{\alpha} \\
\approx 240^{\beta}\end{array}$ & $\begin{array}{l}<30^{\alpha} \\
<10^{\beta}\end{array}$ & $\begin{array}{l}<90^{\alpha} \\
<20^{\beta}\end{array}$ \\
\hline & $\begin{array}{l}\text { isotropic } \\
\text { aquifer }\end{array}$ & & & $\approx 80^{\alpha \beta}$ & $\approx 80^{\alpha \beta}$ & $<10^{\alpha \beta}$ & $<10^{\alpha \beta}$ \\
\hline
\end{tabular}

${ }^{\alpha} V[\ln K]=1,{ }^{\beta} V[\ln K]=0.3$

Table 1 shows results for two different heterogeneity levels: $V[\ln K]=0.3$ and $V[\ln K]=1$. The difference between these two heterogeneity levels in the critical distance from the source where $S_{R}$ falls below $1 \%$ is significant only for longlasting leakage in the extreme stratified aquifer case.

The effect of aquifer structure (stratified or isotropic) on that critical distance is generally not significant for short-pulse releases, as long as the aquifer logconductivity variance $V[\ln K]$ is, as often assumed, about 1 or less $[1,2]$. In the short-pulse release case, the critical distance where $S_{R}$ falls below 1\% (or any other chosen level) generally depends much more on the order of magnitude of the relative attenuation rate $\lambda\left(n x_{s}\right) /\left(K_{g} J\right)$ and concentration limit $C_{T} / C_{0}$ than on the commonly unknown details of aquifer structure and heterogeneity (within the limit $V[\ln K] \leq 1)$. This means that the necessity of immediate emergency measures for fast removal of accidentally released contaminants may be judged on basis of relatively straightforward order-of-magnitude assessment of the relations $C_{T} / C_{0}$ and $\lambda\left(n x_{s}\right) /\left(K_{g} J\right)$.

For long-lasting leakage of contaminants, the distance from the source where $S_{R}$ falls below 1\% (or any other chosen level of risk acceptance) may be much 
longer in the stratified aquifer than in the isotropic aquifer case. But this effect of heterogeneity structure may be irrelevant for environmental management because for $\lambda\left(n x_{s}\right) /\left(K_{g} J\right) \leq 0.01$, for example, the risk to exceed most of the plausible relative concentration limits $C_{T} / C_{0}$ is highly likely to remain above $1 \%$ at distances 240 times the source zone extent, independently of aquifer heterogeneity structure and magnitude. This may serve as a clear indication to prioritise remediation initiatives and investigations in contaminated land cases that are assessed to fall within this order-of-magnitude category.

Furthermore, for $\lambda\left(n x_{s}\right) /\left(K_{g} J\right) \geq 1$, the long-lasting leakage risk is instead highly likely to decline below $1 \%$ at distances closer than 50 times the source zone extent for all concentration limits $C_{T} / C_{0} \geq 0.01$, again independently of specific aquifer heterogeneity structure and magnitude details. This indicates that contaminated land cases within this order-of-magnitude category may not be highly prioritised for remediation if there are no particular protected or health/environmentally sensitive water environments within that distance from the source zone. Finally, for $\lambda\left(n x_{s}\right) /\left(K_{g} J\right) \approx 0.1$, and also for $\lambda\left(n x_{s}\right) /\left(K_{g}\right) \approx 1$ if the concentration limit $C_{T} / C_{0} \leq 0.001$, the distance at which the long-lasting leakage risk declines below $1 \%$ varies greatly depending on aquifer heterogeneity structure. This indicates that contaminated land cases within this order-ofmagnitude category should be prioritised for further site characterisation investigations focused on obtaining better estimates of aquifer heterogeneity and structure and their risk effects.

\subsection{Application for Forsmark}

In this section, we show the results of the GIS-based hydrological transport model of solute transport from the whole Forsmark catchment area (i.e., from all of the $10 \times 10 \mathrm{~m}$ cells in the model area) to the coast.

Fig. 3 and Fig. 4 illustrate how advective travel time variability for each cell increases the expected mass delivery fraction $E[\alpha]$ from each cell. For any given attenuation rate $\lambda, E[\alpha]$ varies in space due to differences in expected travel time from different cell locations to the coast. The different expected travel times range from less than 1 day to 12 years within the catchment area. As we have
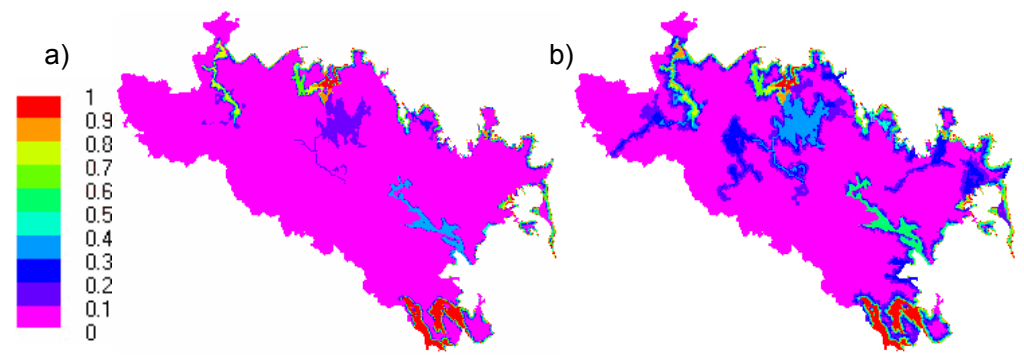

Figure 3: Expected delivery factors (fraction of released solute that will reach the coast) for linear attenuation rate $\lambda=10 /$ years if (a) $V[\ln T]=0$ and (b) $V[\ln T]=1$. 


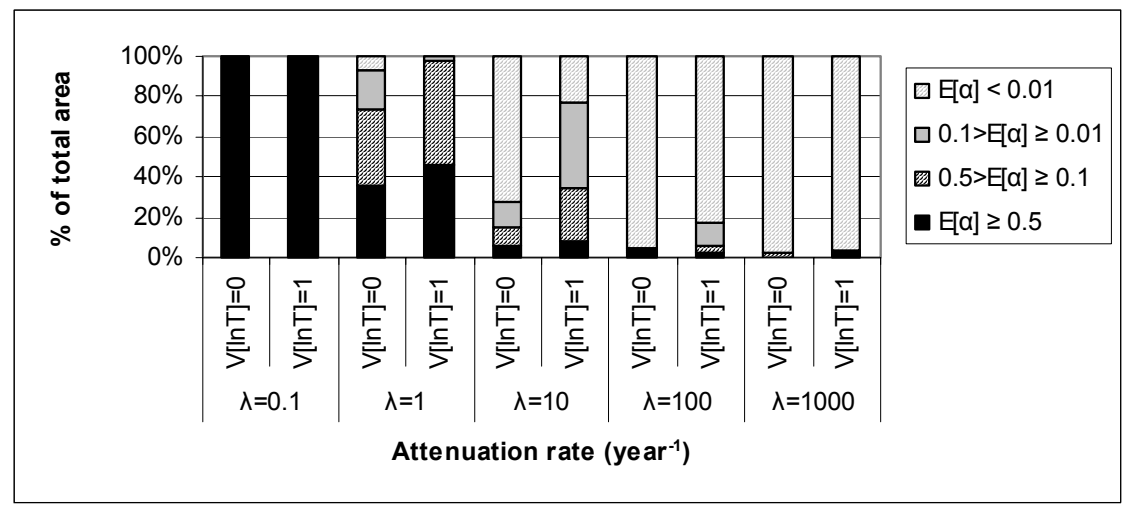

Figure 4: Comparison of the percentage of total catchment area corresponding to different expected delivery factor intervals between homogeneous $(V[\ln T]=0)$ and heterogeneous $(V[\ln T]=1)$ conditions.

already seen in the theoretical part of this study, the ratio between attenuation rate $\lambda$ and mean advective travel time may be considerably more important for delivered contaminant mass (and associated environmental risk) than aquifer heterogeneity details, which in this application example are represented in terms of travel time variance $V[\ln T]$ for each cell.

For $\lambda=10 /$ year, $E[\alpha]>0.1$ only for model cells in and around the surface water network and very close to coastal outlets, regardless if travel time variability is accounted for or not. Hence, for $\lambda \geq 10$ /year, less than $10 \%$ of contaminant mass released anywhere in the catchment area is likely to reach the coast, unless the mass is released more or less directly into the surface water network. However, if $E[\alpha]=0.01$ rather than $E[\alpha]=0.1$ is a critical environmental limit, the effect of aquifer heterogeneity expressed through $V[\ln T]$ may be crucial; the fraction of the total area where $E[\alpha]>0.01$ is small if $V[\ln T]=0$, whereas it is about $1 / 4$ if $V[\ln T]=1$. For higher attenuation rates $\lambda \geq 100 /$ year, $E[\alpha]>0.01$ only in a small part of the area also if $V[\ln T]=1$.

For $\lambda=1 /$ year, $E[\alpha]>0.01$ in practically the entire catchment area, independently of whether travel time variability is taken into account or not. For still lower attenuation rate $\lambda=0.1 /$ year, $E[\alpha]>0.5$ in $98 \%$ of the area also when $V[\ln T]=0$.

However, aquifer heterogeneity and associated travel time variability does not only affect mean delivery factors $E[\alpha]$. It also yields uncertainty about which different $\alpha$ value around $E[\alpha]$ that may actually prevail in a real field situation. This uncertainty may be quantified in terms of the variance $V[\alpha]$. For assumed normally distributed $\alpha$, the probability, or risk, that any particular $\alpha$ realisation will exceed $E[\alpha]$ is as high as 0.5 . The risk that $E[\alpha]+2$ standard deviations $\left(S D[\alpha]=V[\alpha]^{1 / 2}\right)$ will be exceeded is further 0.02 , and the risk that $E[\alpha]+3 S D[\alpha]$ will be exceeded is 0.001 . 
Fig. 5 shows the fraction of total catchment area from which $E[\alpha]$, $E[\alpha]+2 S D[\alpha]$ and $E[\alpha]+3 S D[\alpha]$ may be expected to be greater than 0.01 for different $\lambda$. Such uncertainty analysis, in addition to only expected result analysis, provides better guidance for environmental planning and management of contaminated land sites. For instance, if $\lambda=100 /$ year, $E[\alpha]+3 S D[\alpha]$ is greater than 0.01 only in and directly around the surface water network and along the sea shore. Hence, one can in this case with great certainty ( 0.999 probability) say that less than $1 \%$ of any contaminant mass released in all other parts of the catchment area is likely to reach the coast.

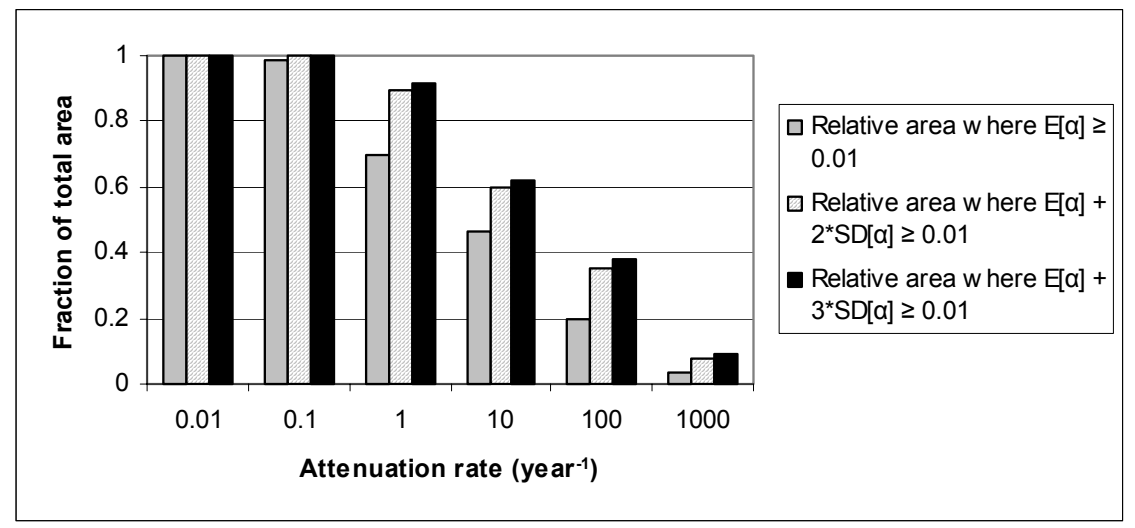

Figure 5: Fraction of the model area from which the expected delivery factor $E[\alpha], E[\alpha]+2$ standard deviations $(S D[\alpha])$, and $E[\alpha]+3$ standard deviations respectively exceeds 0.01 for different first-order attenuation rates $\lambda$. For a normally distributed $\alpha$, the probability of exceedence of $E[\alpha], E[\alpha]+2 S D[\alpha]$, and $E[\alpha]+3 S D[\alpha]$ is $0.5,0.02$ and 0.001 respectively.

\section{Conclusions}

The site-specific results for the Forsmark catchment area support the purely theoretical results in indicating that approximate order-of magnitude estimates of mean advective travel time and attenuation rate may in many cases be sufficient to assess if contaminant release is likely to result in unacceptable contaminant discharges into downstream water recipients. Complex aquifer heterogeneity and structure details may be important within an identifiable and limited critical range of the relation between characteristic average time scales for physical contaminant transport and physical or (bio)geochemical contaminant attenuation. In general, the methodology that has been outlined and used in this study may be a powerful, yet relatively simple tool for assessing environmental risk propagation downstream of contaminated land. 


\section{Acknowledgements}

We thank the Swedish Rescue Services Agency (SRV), the Geological Survey of Sweden (SGU), and the Swedish Nuclear Fuel and Waste Management Co (SKB) for the funding of this study.

\section{References}

[1] Dagan, G. Flow and Transport in Porous Formations. Springer Verlag, Berlin, 1989.

[2] Rubin, Y. Applied Stochastic Hydrogeology. Oxford University Press, New York, 2003.

[3] Cvetkovic, V., Cheng, H., Wen, X.H. Analysis of nonlinear effects on advective tracer transport in heterogeneous aquifers using Lagrangian statistics of travel time. Water Resour. Res., 32, 1671-1680, 1996.

[4] Destouni, G. Prediction uncertainty in solute flux through heterogeneous soil. Water Resour. Res., 28, 793-801, 1992.

[5] Destouni, G., Graham, W. The influence of observation method on local concentration statistics in the subsurface. Water Res. Res., 33, 663-676, 1997.

[6] Jarsjö, J., Shibuo, Y., Prieto, C. and Destouni, G., GIS-based modelling of coupled groundwater - surface water hydrology in the Forsmark and Simpevarp areas. SKB Report R-05-67, 2006.

[7] Jarsjö, J., Shibuo, Y., Destouni, G. Spatial distribution of unmonitored inland water flows to the sea. Journal of Hydrology, 348, 59-72, 2008.

[8] Johansson, P.-O., Werner, K., Bosson, E., Juston, J. Description of climate, surface hydrology, and near-surface hydrology. Preliminary site description. Forsmark area - version 1.2. SKB Report R-05-06, 2005.

[9] Brunberg, A.-K., Carlsson, T., Blomqvist, P., Brydsten, L. and Strömgren, M., Identification of catchments, lake-related drainage parameters and lake habitats, SKB Report P-04-25, 2004.

[10] Fredriksson, D., Peatland investigation Forsmark, SKB Report P-04-127, 2004.

[11] Johansson, P.-O., Drilling and sampling in soil. Installation of groundwater monitoring wells and surface water level gauges. SKB Report P-03-64, 2003.

[12] Nilsson, A.-C., Borgiel, M., Sampling and analyses of surface waters. Results from sampling in the Forsmark area, March 2003 to March 2004. SKB P-04-146, 2004. 